\title{
Morbidity Pattern among Patients Attending Urban Health Centre in North India
}

Authors

\section{Dr Abdul Rouf ${ }^{1}$, Dr Mahbooba Rasool ${ }^{1}$, Dr S M Salim Khan ${ }^{1}$, Dr Mariya Amin ${ }^{1}$, Dr Sheikh Mohd Saleem ${ }^{1}$}

${ }^{1}$ Department of Community Medicine, Government Medical College Srinagar

Corresponding Author

\section{Dr Abdul Rouf}

Naz Enclave Panthachowk Srinagar, J\&K, India, 191101

9419974600, Email: a.rouf.dr@gmail.com

\section{ABSTRACT}

Background: The study aims at studying morbidity pattern of communicable and non-communicable diseases and seasonal variation of OPD patients of an Urban Primary health Centre Harwan under Department of Community Medicine, Government Medical College Srinagar. The objectives of the study are to assess the morbidity pattern of patients as per age, sex, and season and to determine the seasonal variation of morbidities.

Methods: This retrospective record based study was conducted for the duration of one year from July 2016 to June 2017. The data were collected from the OPD registers of Medical officers and analysis was done on the basis of new patients only. The patients were grouped into age groups of <5 year; 5-15 years; 16-45 years; >45years.

Results: The total number of new episodes of illnesses that were treated in the outpatient department from July 2016 to June 2017 was 6083. Patients having age (>15 years) constituted about 82\%. Overall the respiratory disorders were the most common about $20 \%$, followed by the musculoskeletal disorders $8.64 \%$, urinary tract infections $8.10 \%$, gastrointestinal disorders about (8\%) and diarrhoeal diseases (7.9\%). Most of the morbidities registered in OPD, were found more in winter and rainy season.

Conclusions: The study gives an outline of the morbidity pattern of patients attending an urban health centre over a period of one year. This knowledge would help the health care administrators to plan, practice and deliver, high quality services as per the community need.

Keywords: Morbidity pattern, Seasonal variation, Urban health centre.

\section{INTRODUCTION}

Primary Health Care is an integral part of the health system and the overall social and economic development of the community. ${ }^{1}$ A good understanding of the distribution and magnitude of health problems is essential for accessing the burden of various diseases at the grass-root level. An analysis of the morbidity pattern and seasonal variation of diseases in urban PHC where tertiary health care institutions take much of the load of the patients can help in the setting the policies of the health care and can optimize the use of resources.

The overall objective of IPHS is to provide health care that is quality oriented and sensitive to the needs of the community. ${ }^{2}$ Earlier, burden of 
communicable diseases was much higher than non-communicable diseases, but in view of rapid change in lifestyle, Non-communicable diseases are increasing worldwide and the gap has reduced drastically causing double burden of disease in developing counties like India. More than 40 million people die annually from NCDs (70\% of global deaths), including more than 15 million people who die too young between the ages of 30 and 69 . Premature deaths account for over $80 \%$ of the burden of these in low and middle income countries. $^{3,4}$

In India nearly half of all deaths are due to Noncommunicable Diseases (NCDs). In spite of the declining mortality and changing morbidity pattern, India is still combating the traditional infectious diseases that continue to contribute to a heavy disease burden and take a sizeable toll. ${ }^{5}$ Continuous monitoring of the changing pattern of the diseases help in timely intervention in disease control programs. Moreover, the geographical variation of diseases must be taken into account and to carry out continuous surveillance of different diseases in hospitals so that reliable and updated data aretimely available for health administrators to plan, implement and evaluate disease control and prevention programme strategies. $^{6}$

Kashmir being different from rest of the India for its beautiful climate all throughout the year. It has a typical European climate that is widely categorized into four seasons as spring, summer, autumn and winter. ${ }^{7}$

In view of the above facts, the present study aims at studying morbidity pattern of communicable and non-communicable diseases and seasonal variation of OPD patients of an Urban Primary health Centre Harwan under Department of Community Medicine, Government Medical College Srinagar. The objectives of the study are to assess the morbidity pattern of patients as per age, sex, and season and to determine the seasonal variation of morbidities.

\section{METHODS}

A retrospective record based study carried out amongst patients who attended the OPD at Urban Primary health Centre Harwan of the Department of Community Medicine, Government Medical College Srinagar during the period of one year from July 2016 to June 2017. The PHC caters to a population of about 23000, which includes five sub centres attached to it. The data was collected from the OPD registers of the Medical officers of PHC Harwan. OPD managed by Medical Officers in the PHC providing 10AM to 4PM services for six days in a week with an average patient attendance of about 60 patients per day. Patient details and diagnosis provided by physicians were documented in the morbidity register. Information like age, sex, residence, new or old case and principal diagnosis were extracted from the registers. . The analysis was done on the basis of new patients only and classified into various Communicable and Non-Communicable diseases. The patients were grouped into age groups of $<5$ year; 5-15 years; 16-45 years; >45years. . The Statistical Package for the Social Sciences (SPSS) Version 23 and Excel 2016 was used for statistical analysis. Ethics clearance was taken for the institutional ethical committee.

\section{RESULTS}

The total number of new episodes of illnesses that were treated in the outpatient department from July 2016 to June 2017 was 6083. Adults (>15 years) constituted about $82 \%$. (Table 1) Overall the respiratory disorders were the most common about 20\%(in males $22.28 \%$ and in females $17.70 \%)$, followed by the musculoskeletal disorders $8.64 \%$ (in males $7.65 \%$ and in females $9.56 \%$ ), urinary tract infections $8.10 \%$ (in males $6.66 \%$ and in females $9.43 \%$ ), gastrointestinal disorders about (8\%) and diarrhoeal diseases (7.9\%). Females outnumbered males in almost all diseases except URTI, Viral Fever and Injury and Accidents(Table 2) The majority of patients coming to Urban PHC Harwan were having Communicable diseases and the mostly reported 
were URTI (19.90\%) followed by Acute gastroenteritis (7.90\%), Viral fever (5.11\%). Among Non-communicable diseases Musculoskeletal pains (8.64\%) followed by Hypertension (7.51\%), Gastritis (7.98\%) Injury and Accidents (4.86\%). Table 2. Most of the morbidities registered in OPD, were found more in winter and rainy season. The seasonal trend of most common diseases showed an increase in the number of cases suffering from URTI, Bones and joint diseases and Viral fever during winters and rainy season(Table 3). There were almost uniform cases of Acute gastroenteritis except in Summer which showed a decline in number of cases registered (Fig 1).

Table -1: Distribution of OPD Patients according to the Age \& Sex of Persons

\begin{tabular}{|l|c|c|c|c|c|c|}
\hline \multirow{2}{*}{$\begin{array}{l}\text { Age } \\
\text { (in years) }\end{array}$} & \multicolumn{2}{|c|}{ Male } & \multicolumn{2}{c|}{ Female } & \multicolumn{2}{c|}{ Both } \\
\cline { 2 - 7 } & $\begin{array}{c}\text { No. of } \\
\text { Patients }\end{array}$ & $\begin{array}{c}\text { Percentage } \\
(\%)\end{array}$ & $\begin{array}{c}\text { No. of } \\
\text { Patients }\end{array}$ & $\begin{array}{c}\text { Percentage } \\
(\%)\end{array}$ & $\begin{array}{c}\text { No. of } \\
\text { Patients }\end{array}$ & $\begin{array}{c}\text { Percentage } \\
(\%)\end{array}$ \\
\hline$<5$ & 173 & 57.66 & 127 & 42.33 & 300 & 4.93 \\
\hline $5-15$ & 435 & 54.17 & 368 & 45.82 & 803 & 13.20 \\
\hline $16-45$ & 1409 & 44.85 & 1732 & 55.14 & 3141 & 51.63 \\
\hline$>45$ & 909 & 49.42 & 930 & 50.57 & 1839 & 30.23 \\
\hline Total & 2926 & 48.10 & 3157 & 51.89 & 6083 & \\
\hline
\end{tabular}

Table 2: Distribution of the reported cases of diseases as per Sex

\begin{tabular}{|l|c|c|c|c|c|c|}
\hline \multirow{2}{*}{ Morbidity } & \multicolumn{2}{|c|}{ Males } & \multicolumn{2}{c|}{ Females } & \multirow{2}{*}{ Total } & $\%$ \\
\cline { 2 - 5 } & Cases & $\%$ & Cases & $\%$ & \multirow{2}{*}{$\%$} \\
\hline Respiratory Diseases & 652 & 22.28 & 559 & 17.70 & 1211 & 19.90 \\
\hline Diarrhoeal Diseases & 224 & 7.65 & 257 & 8.14 & 481 & 7.90 \\
\hline UTI & 195 & 6.66 & 298 & 9.43 & 493 & 8.10 \\
\hline GI Diseases & 223 & 7.62 & 263 & 8.33 & 486 & 7.98 \\
\hline Eye diseases & 45 & 1.53 & 43 & 1.36 & 88 & 1.44 \\
\hline ENT Diseases & 71 & 2.42 & 69 & 2.18 & 140 & 2.30 \\
\hline Skin Diseases & 83 & 2.83 & 88 & 2.78 & 171 & 2.81 \\
\hline B \& J Diseases & 224 & 7.65 & 302 & 9.56 & 526 & 8.64 \\
\hline Injury \& Accidents & 165 & 5.63 & 131 & 4.14 & 296 & 4.86 \\
\hline Hypertension & 218 & 7.45 & 239 & 7.57 & 457 & 7.51 \\
\hline Fever & 168 & 5.74 & 143 & 4.52 & 311 & 5.11 \\
\hline Anaemia & 23 & 0.78 & 57 & 1.80 & 80 & 1.31 \\
\hline Others & 635 & 21.70 & 708 & 22.42 & 1343 & 22.07 \\
\hline Total & 2926 & & 3157 & & 6083 & \\
\hline
\end{tabular}

Table 3: Distribution of the reported cases of diseases in different seasons.

\begin{tabular}{|c|c|c|c|c|c|c|c|c|}
\hline \multirow{3}{*}{ Morbidity } & \multicolumn{8}{|c|}{ Seasons } \\
\hline & \multicolumn{2}{|c|}{ Spring } & \multicolumn{2}{|c|}{ Summer } & \multicolumn{2}{|c|}{ Autumn } & \multicolumn{2}{|c|}{ Winter } \\
\hline & Cases & $\%$ & Cases & $\%$ & Cases & $\%$ & Cases & $\%$ \\
\hline Respiratory Diseases & 321 & 20.83 & 277 & 27.31 & 249 & 14.49 & 364 & 20.11 \\
\hline Diarrhoeal Diseases & 126 & 8.17 & 42 & 4.14 & 160 & 9.31 & 153 & 8.45 \\
\hline UTI & 136 & 8.82 & 67 & 6.60 & 151 & 8.78 & 139 & 7.67 \\
\hline GI Diseases & 123 & 7.98 & 64 & 6.31 & 164 & 9.54 & 135 & 7.45 \\
\hline Eye diseases & 27 & 1.75 & 6 & 0.59 & 28 & 1.62 & 27 & 1.49 \\
\hline ENT Diseases & 33 & 2.14 & 18 & 1.77 & 55 & 3.20 & 34 & 1.87 \\
\hline Skin Diseases & 52 & 3.37 & 26 & 2.56 & 58 & 3.37 & 35 & 1.93 \\
\hline B \& J Diseases & 147 & 9.53 & 67 & 6.60 & 155 & 9.02 & 157 & 8.67 \\
\hline Injury \& Accidents & 80 & 5.19 & 32 & 3.15 & 93 & 5.41 & 91 & 5.02 \\
\hline Hypertension & 115 & 7.46 & 81 & 7.98 & 102 & 5.93 & 159 & 8.78 \\
\hline Fever & 68 & 4.41 & 36 & 3.55 & 91 & 5.29 & 116 & 6.40 \\
\hline Anaemia & 18 & 1.16 & 8 & 0.78 & 41 & 2.38 & 10 & 0.55 \\
\hline Others & 295 & 19.14 & 290 & 28.59 & 371 & 21.59 & 390 & 21.54 \\
\hline Total & 1541 & 25.33 & 1014 & 16.66 & 1718 & 28.24 & 1810 & 29.75 \\
\hline
\end{tabular}




\section{JMSCR Vol||05||Issue||08||Page 26574-26579||August}

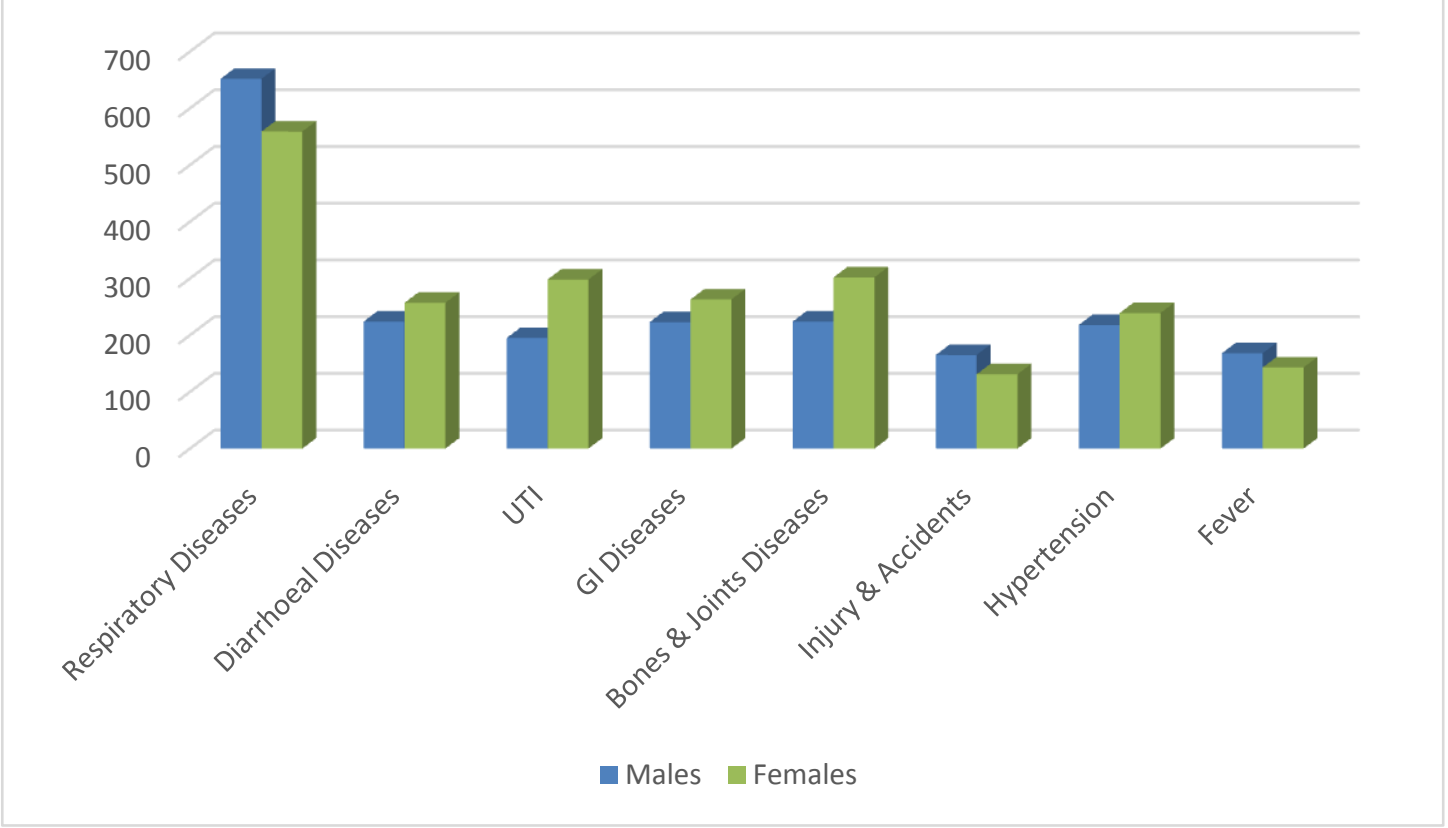

Figure 1: Showing morbidity pattern according to Sex

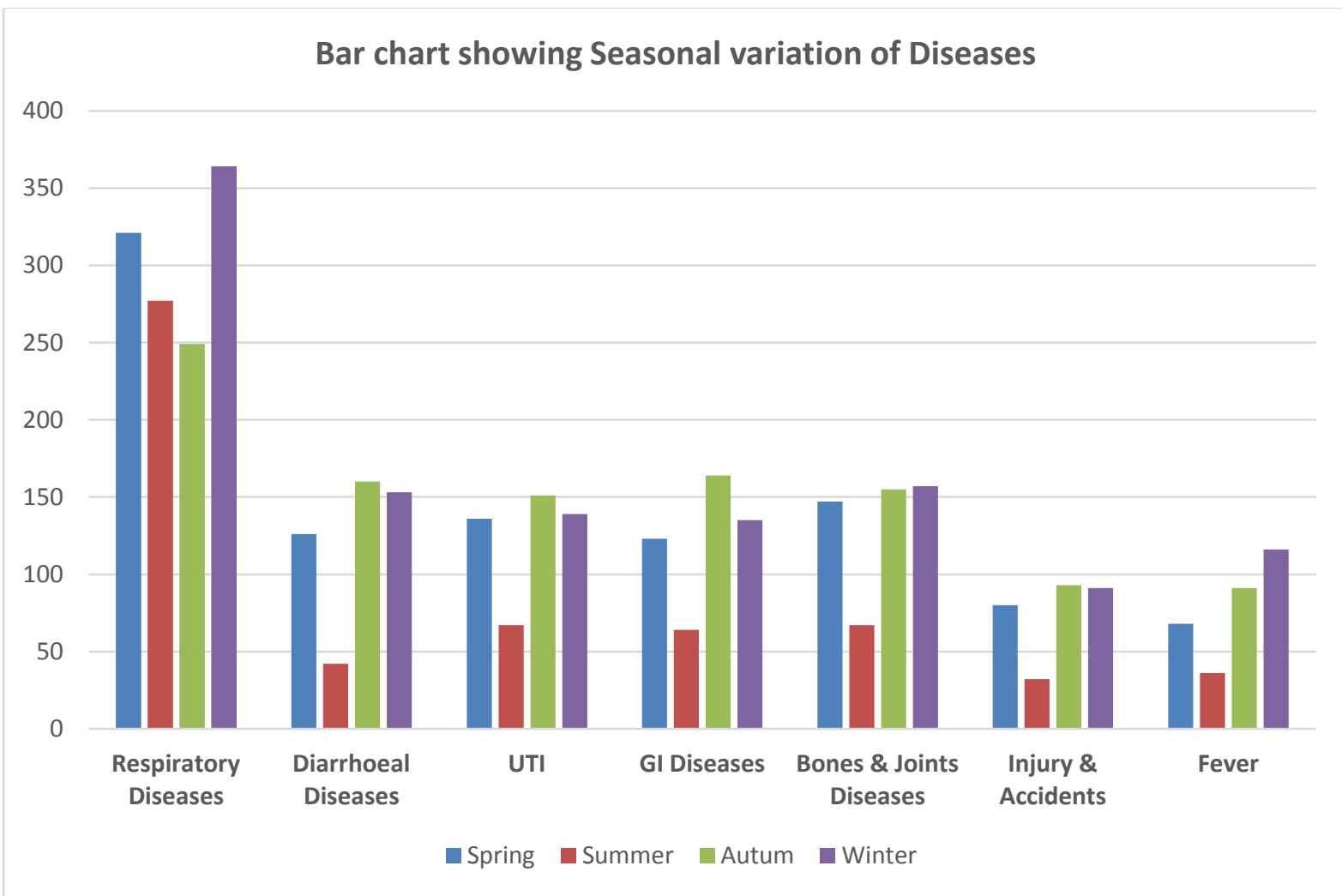

Figure 2: Showing morbidity pattern according to Season.

\section{DISCUSSION}

The results of the study showed that most of the patients reporting to the PHC were above 15 years of age $(82 \%)$. Similar results were obtained in earlier study conducted by (Arti Gupta et al 2015) in Urban Health centre, Madhya Pradesh, Central India $^{8}$ and with the findings of other similar studies conducted in the past. ${ }^{9,10}$ It was found that out of total reported cases at OPD, Respiratory diseases $(20.0 \%$ ) GIT diseases $(8.0 \%)$ Diarrhoeal diseases $(8.0 \%)$ Bone and Joint diseases $(8.64 \%)$ and Hypertension constituted the principle cause of morbidity in this study population. The similar pattern was also reported in different studies. ${ }^{11,12}$ 
Higher proportion of Musculoskeletal disorders followed by Hypertension among Noncommunicable diseases have been found in similar studies. ${ }^{13-18}$ This discrepancy in the occurrence of various diseases could be ascribed to the variation in the environmental factors in the different geographic areas, Kashmir beinghaving a humid subtropical climate, much cooler than rest of India. $^{7}$ Overall the prevalence of Noncommunicable diseases were reported less in this study despite the rising trends at national level. Infectious and parasitic diseases were reported in less percentage and it might be due to better immunization coverage activities in Urban population.

In children, the most common illness reported was Acute respiratory tract infections, Acute gastroenteritis, Injuries and Viral fever. Study conducted in Aligarh among under 5 children found that respiratory and skin disorders were the most common illnesses. ${ }^{19}$

Seasonal variation showed that maximum burden of OPD patients occurred during Winters followed by Rainy seasons. However the results shown by a study in Chandigarh by (Vikas Yadav et al, 2015 ) revealed more occurrence of diseases in Winter followed by Summer. ${ }^{20}$ The possible reasons seem to be the climatic difference in Kashmir with rest of the India.

\section{LIMITATION OF THE STUDY}

The study was conducted in a single health facility and secondary data were used for drawing inferences, hence generalization of findings needs due concern. The study does not explore causes of the observed patterns also.

\section{CONCLUSION AND RECOMMENDATIONS}

The study gives an outline of the morbidity pattern of patients attending an urban health training centre over a period of one year, which would help the health care providers and administrators to plan, practice and deliver, high quality services as per the community needs. The reasons for the seasonal variation of most of the diseases need to be explored and it is highly recommended that long term studies with wider coverage will act as a perfect tool for the health planners to plan better strategies.

\section{ACKNOWLEDGEMENTS}

Authors would like to thank Dr. S.M. Salim Khan , Head of the Department of Community Medicine, Government Medical College Srinagar for his contribution and support to complete this study.

Funding: No funding sources

Conflict of interest: None declared

Ethical approval: The study was approved by the ethical committee of Government Medical College Srinagar.

\section{REFERENCES}

1. Declaration of Alma-Ata. International Conference on Primary Health Care, Alma-Ata, USSR, 6-12 September 1978. Available from http://www.who.int/publications/almaata_ declaration_en.pdf [Accessed on 21.07.2107 at 7:15 AM]

2. Welfare F. Indian Public Health Standards ( IPHS ) For Primary Health Centres Contents : 2006;(March):1-9

3. World health organization, Geneva. Global action plan for prevention and control of non-communicable diseases, 2013-2020. (Fact sheet, Updated June 2017)

4. Available from http://www.who.int/mediacentre/factsheets /fs355/en/[Accessed on 21.07.2107 at 8:05 $\mathrm{AM}]$.

5. Baridalyne Nongkynrih, BK Patro, Chandrakanta S Pandav. Current Status of Communicable and Non-communicable Diseases in India. Japi. 2004: 52; 118-23.

6. M.K. Sharma, D. Kumar. Health Care Utilization Pattern for Communicable and Non-Communicable Diseases in a Tertiary Care Health Facility in Chandigarh, India. 
The Internet Journal of Health. 2007; Volume 7 Number 2.

7. Available

from

https://www.kashmirincoming.com/season s-in-j\&k [Accessed on 21.07.2107 at 8:25 $\mathrm{AM}]$.

8. Gupta A, Reddy BV, Nagar MK. Portfolio of Outpatients Attending Centre for Urban Health, Madhya Pradesh, Central India. 2015;4-7.

9. Arun A, Gupta P, Srivastava JP, Prakash D. A study of the morbidity pattern amongst patients attending the OPD at Urban health training centre, Era ${ }^{\text {ee }} \mathrm{s}$ Lucknow Medical college and Hospital, Lucknow. Int J Adv Res. 2013;1(10):90613.

10. Patel MV, Desai GJ, Bhavsar BS. Profile of patients attending a general practitioneres clinic In Vadodara city, Gujarat. Int J Health Sci Res. 2014;4(2):12-5.

11. Dutta Jyant Kumar and Banerjee RR. "Morbidity Pattern of Out Patient's Attendance", Indian Journal of Paediatrics, 37: 267, 1970.

12. Seal SC et al. "General Health Survey of Talcher Community Development Block", Orissa, Director General of Health Services, New Delhi, 1958.

13. Lai MS, Chu CS, Lin SH, Lin MS. Prescribing patterns in primary health care in Taiwan. Int $\mathbf{J}$ ClinPharmacolther 1995;33:437-441

14. Jyvasjarvi S, Keinanen-Kiukaanniemi S, Vaisanen E, Lari-vaara P, Kivela SL. Frequent attenders in a Finnish health centre: Morbidity and reasons for encounter. Scand J Prim Health Care. 1998; 16:141-8.

15. Shankar R, Kumar P, Rana M, Dubey A, Shenoy N. A comparative study of drug utilisation at different levels of the primary healthcare system in Kaski district, West- ern Nepal. The New Zealand Medical Journal. 2003;116:1-8

16. Sharma MK, Bhatnagar T, Goel NK, Verma A, Swami HM. Operationalisation of surveillance of communicable diseases in Chandigarh. J Commun Dis. 2005; 37:197-202.

17. Dharmaratne S, Agampodi S, Dassanayaka S, Kuma-rihami P, Ratnayake A, Wickramathilake S. Disease bur-den assessment beyond in-patient data: A morbidity pro-file assessment of outpatients. Int J Prev Med. 2012;3:730-2.

18. Gupta A, ChellaiyanV, Lohiya A, Rizwan SA, Upadhyay RP, Palanivel C. Morbidity Profile of Out-Patients At-tending a Primary Health Centre in Rural Puducherry, South India. Natl J Community Med. 2014; 5(4): 424-7.

19. Ansari MA, Khan Z, Khalique N, Siddiqui AR. Health profile of under fives in rural areas of Aligarh, India. Indian J Prev Soc Med. 2008;39(3-4):91-93.

20. Sharma MK, Bhatnagar T, Goel NK, Verma A, Swami HM. Operationalisation of surveillance of communicable diseases in Chandigarh. J Commun Dis. 2005; 37:197-202. 